\title{
Revista Colombiana de

\section{Hipoplasia de la valva posterior de la válvula mitral y válvula aórtica bicúspide. Una muy rara asociación para encontrar en un paciente adulto}

\author{
Luis F. Sánchez-Solanilla ${ }^{a, *}$, José F. Zuluaga-Rojas ${ }^{b}$ y Jaime Rodríguez-Martin ${ }^{b}$ \\ a Ecocardiografía Universidad del Rosario, Bogotá, Colombia \\ b Servicio de Cardiología no Invasiva, Fundación Clínica Shaio, Bogotá, Colombia
}

Recibido el 28 de junio de 2017; aceptado el 20 de abril de 2018

Disponible en Internet el 26 de julio de 2018

\section{PALABRAS CLAVE \\ Válvula mitral; \\ Cardiopatías \\ congénitas; \\ Adulto}

\begin{abstract}
Resumen Las cardiopatías congénitas representan un reto diagnóstico para el clínico, sobre todo si su presentación es en el adulto. Las anomalías de este tipo que se observan sobre la válvula mitral pueden presentarse de forma aislada o en conjunto con otros defectos cardiacos. Se expone un caso de hipoplasia severa de la valva posterior de la válvula mitral, entidad que en condiciones normales es fatal antes de nacer o muy sintomática durante la niñez, pero cuya presentación tardía es extremadamente rara y difícil de encontrar en el adulto. Este es el primer caso reportado no solo en nuestro país sino en todo Suramérica.

(c) 2018 Sociedad Colombiana de Cardiología y Cirugía Cardiovascular. Publicado por Elsevier España, S.L.U. Este es un artículo Open Access bajo la licencia CC BY-NC-ND (http:// creativecommons.org/licenses/by-nc-nd/4.0/).
\end{abstract}

Hypoplasia of the posterior mitral valve leaflet and bicuspid aortic valve. A very rare combination to find in an adult patient

Abstract The congenital heart diseases are a diagnostic challenge for the clinician, particularly when they are presented in an adult. These types of anomalies that are observed in the mitral valve can be presented in isolated form or together with other heart defects. The case is presented of a patient with severe hypoplasia of the posterior mitral valve leaflet. This anomaly is, under normal conditions, fatal before birth or very symptomatic during childhood, and its delayed presentation is extremely rare and difficult to find in the adult. This the first case reported, not only in this country, but in the whole of South America.

(c) 2018 Sociedad Colombiana de Cardiología y Cirugía Cardiovascular. Published by Elsevier España, S.L.U. This is an open access article under the CC BY-NC-ND license (http:// creativecommons.org/licenses/by-nc-nd/4.0/).

* Autor para correspondencia.

Correo electrónico: luisfer.sanchez@urosario.edu.co (L.F. Sánchez-Solanilla). 


\section{Introducción}

Si hay algo difícil de abordar para un cardiólogo de adultos, es enfrentarse a una cardiopatía congénita de presentación tardía, no solo en el ámbito clínico sino más aún en el área de las imágenes cardiovasculares. Sin embargo, día a día cada vez es más común este tipo de casos que no son exclusivos de la población pediátrica. Muchas de estas entidades están claramente estudiadas y definidas por la literatura, mientras que otras son extremadamente raras de encontrar, casi como un dato anecdótico. He ahí la importancia de describir estas entidades que estimulan al profesional de la Cardiología a estar alerta y fomentar el desarrollo de métodos de evaluación más precisos dentro de las imágenes cardiovasculares.

Se presenta un caso de hipoplasia severa de la valva posterior de la válvula mitral (entidad que no ha sido reportada previamente en la literatura latinoamericana) y válvula aórtica bicúspide en un paciente adulto prácticamente asintomático.

\section{Caso}

Hombre de 59 años, con antecedente de enfermedad coronaria intervenida de manera percutánea en otra institución, con angioplastia e implante de tres stents, dislipidemia y extabaquismo, quien ingresó al servicio de urgencias por cuadro de dolor torácico, disnea y náuseas de 3 horas de evolución. A la revisión por sistemas, clase funcional previa de I/IV de la escala NYHA. Electrocardiograma de ingreso sin cambios agudos y biomarcadores cardiacos negativos. Se hospitalizó con diagnóstico de angina inestable. Se ordenó estudio ecocardiográfico que documentó cardiopatía dilatada de origen isquémico con función sistólica moderadamente deprimida, FE 35\%, válvula aórtica bivalva con jet de insuficiencia excéntrica de grado moderado y válvula mitral con hipoplasia severa de la valva posterior con restricción en su movilidad, presencia de una valva anterior elongada e hipertrofia del músculo papilar posteromedial con hipoplasia del músculo papilar anterolateral, jet de insuficiencia excéntrico que se dirigía hacia las paredes lateral y posterior de la aurícula izquierda de grado leve a moderado, sin estenosis, con orificio regurgitante efectivo por $3 \mathrm{D}$ de $0,2 \mathrm{~cm}^{2}$ (fig. 1). Fue llevado a nueva arteriografía coronaria en la que se encontraron arterias coronarias sin lesiones significativas. Evolucionó de manera satisfactoria y fue dado de alta.

\section{Discusión}

Las anormalidades congénitas de la válvula mitral son entidades bastante infrecuentes con un amplio espectro en su presentación ${ }^{1}$. Suelen clasificarse de acuerdo con el sitio anatómico comprometido en anormalidades de las valvas, las cuerdas tendinosas, los músculos papilares y las comisuras. Dentro del compromiso de las valvas, puede haber hendiduras, tejido valvular accesorio, hipoplasia o agenesia de las valvas; de estas últimas se han reportado pocos casos $^{2-4}$.

Se sabe que en condiciones normales el área de la válvula mitral es típicamente de $4-6 \mathrm{~cm}^{2}$. Tiene dos valvas, la anterior y la posterior. La primera forma la mayor parte de la superficie de cierre, mientras que la segunda tiene una forma de media luna con comisuras pequeñas que la dividen en diferentes segmentos.

La hipoplasia severa de la valva posterior de la válvula mitral es una rara malformación congénita de la válvula mitral que en su mayoría es fatal in útero, pero que ha sido descrita sobre todo en la infancia, asociada a insuficiencia mitral severa ${ }^{4,5}$.
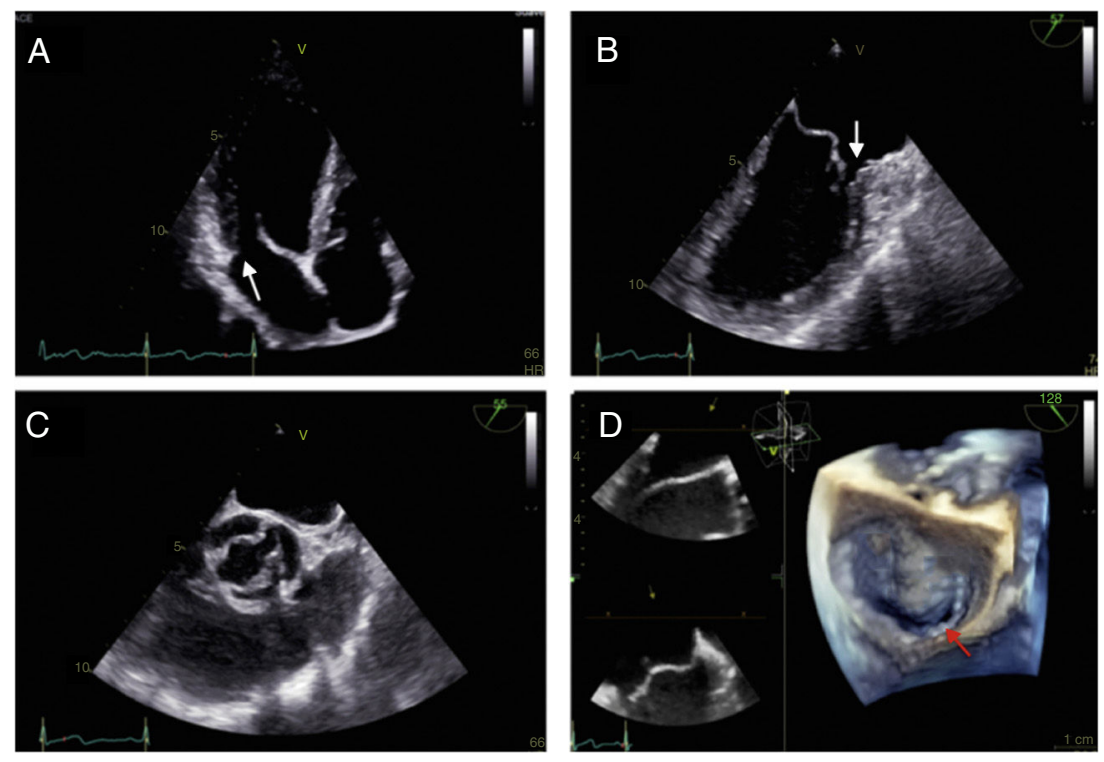

Figura 1 Ecocardiografía transtorácica y transesofágica. Panel $1 \mathrm{~A}$ (apical de 4 cámaras) y $1 \mathrm{~B}$ (2 cámaras esófago medio). Se observa válvula mitral con valva anterior elongada. La flecha blanca señala la valva posterior severamente hipoplásica. Panel $1 \mathrm{C}$ (vista eje corto esófago medio). Se observa la válvula aórtica de apertura bivalva. Panel $1 \mathrm{D}$ (reconstrucción en $3 \mathrm{D}$ de la válvula mitral). La flecha roja señala la valva posterior severamente hipoplásica. 
Aún más inusual es encontrar esta anomalía en la población adulta. Se han reportado muy pocos casos en adultos asintomáticos ${ }^{5-9}$. Algunos de estos reportes describen la asociación de hipoplasia de la valva posterior de la vávula mitral con estenosis del anillo mitral supravalvular y algunos otros con la presencia e insuficiencia valvular de instauración progresiva por dilatación del anillo. Es posible que esta entidad sea más prevalente en la población adulta de lo que se reconoce en la actualidad ${ }^{7}$.

En el caso que se expone, la hipoplasia de la valva posterior de la válvula mitral se asocia con otra anomalía congénita: vávula aórtica bicúspide. Esta enfermedad es preponderante en la población masculina con una relación $3: 1$. Se trata de un problema de valvulogénesis en la cual hay dos valvas desiguales y por lo general se presenta con un rafe central por fusión de dos valvas, aunque su morfología puede variar. Se puede asociar con otras malformaciones congénitas como la estenosis aórtica, la coartación de aorta y, en menor proporción, con hipoplasia del corazón izquierdo, síndrome de Shone, síndrome de Williams y otros ${ }^{10}$. La dilatación de la aorta ascendente es un hallazgo frecuente por disturbio del flujo en su salida a la circulación sistémica. Específicamente, no se ha descrito una asociación clara con otro tipo de malformaciones valvulares.

\section{Conclusiones}

La hipoplasia severa de la valva posterior de la válvula mitral es una anomalía congénita muy rara, difícil de encontrar en la población adulta. Tanto así, que este es el primer caso reportado no solo en Colombia, sino en la literatura latinoamericana, y se convierte en uno de los pocos registrados en el mundo. Dada la rareza de su origen, que no es habitual para el cardiólogo, puede ser una patología subdiagnosticada. Siempre que se halle un disturbio en el flujo valvular, desde el punto de vista ecocardiográfico debe procurarse la mejor valoración anatómica posible, a fin de esclarecer el mecanismo de dicha anomalía. Se espera que el advenimiento de nuevas tecnologías permita caracterizar mejor el estudio de la válvula mitral.

\section{Conflicto de intereses}

Ninguno.

\section{Bibliografía}

1. Ossthoek PW, Wenink ACG, Wisse LJ, Gittenberger de Groot AC. Development of the papillary muscles of the mitral valve: morphogenetic background of parachute-like asymmetric mitral valves and other mitral valve anomalies. J Thorac Cardiovasc Surg. 1998;116:36-46

2. De Agustin JA, Gomez de Diego JJ, Garcia-Fernandez MA, Rodrigo JL, Marcos-Alberca P, Almeria C, et al. Severe hypoplasia of the posterior mitral leaflet: A rare cause of congenital mitral regurgitation assessed by three-dimensional transesophageal echocardiography. Int J Cardiol. 2014;177: e131-2.

3. Kalangos A, Oberhansli I, Baldovinos A, Beghetti M, Friedli B, Faidutti B. Hypoplasia of the posterior leaflet as a rare cause of congenital mitral insufficiency. J Card Surg. 1997;12: 339-42.

4. Cacciolli S, Gelsomino S, Fradella G, Bevillacqua S, Faviili S, Gensini GF. Severe hypoplasia of the posterior mitral leaflet. Ann Thorac Surg. 2008;86:1978-9.

5. Fazlinezhad A, Alvandi Azari M, Bigdellu L. Severe Hypoplasia of Posterior Mitral Valve Leaflet Presented with Atypical Chest Pain: A Case Report. Razavi Int J Med. 2017;5:e41501. doi: 10.5812/rijm.41501.

6. Bär H, Siegmund A, Wolf D, Hardt S, Katus HA, Mereles D. Prevalence of asymptomatic mitral valve malformations. Clin Res Cardiol. 2009;98:305-9.

7. Shah J, Jain T, Shah S, Mawri S, Ananthasubramaniam K. Rare case of unileaflet mitral valve. J Cardiovasc Ultrasound. 2016;24:168-9.

8. Bacich D, Braggion G, Faggian G. Hypoplasia of the posterior mitral leaflet: A rare cause of mitral regurgitation in adulthood. Echocardiography. 2017;00:1-2

9. Yazdan-ashoori P, Rohani A, Mulji AS, Spall HGC. Van. Hypoplasia of the posterior mitral valve leaflet detected in late adulthood. Cardiovascular flashlight. Eur Heart J. 2015;36,14:456. Disponible en: https://doi.org/10.1093/eurheartj/ehu335.

10. Siu SC, Silversides CK. Bicuspid aortic valve disease. JACC. 2010;55:2789-800. 